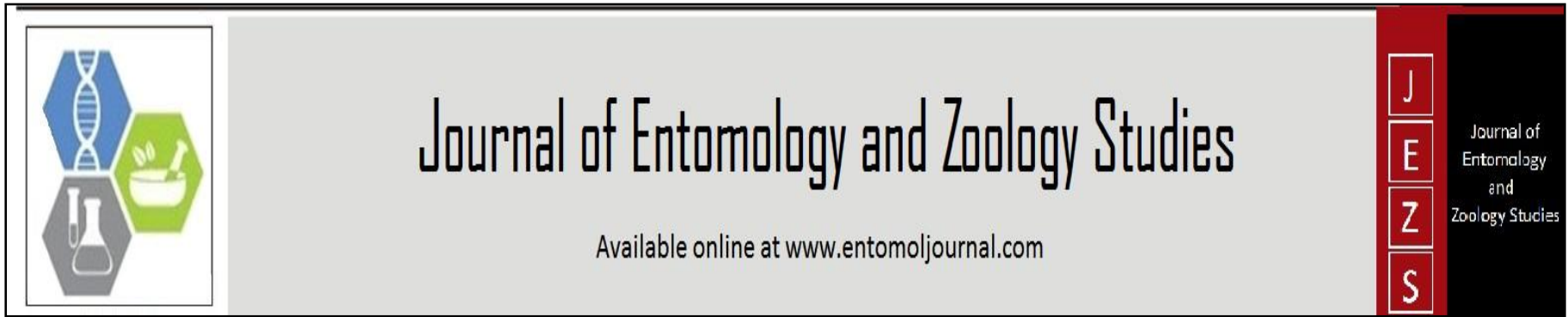

E-ISSN: 2320-7078

P-ISSN: 2349-6800

www.entomoljournal.com

JEZS 2020; 8(5): 1445-1448

(C) $2020 \mathrm{JEZS}$

Received: 25-07-2020

Accepted: 27-08-2020

Amanullah Tantray

Sant Baba Bhag Singh

University, Khlala, Jalandhar,

Punjab, India

Dr. Amrita Kumari

Sant Baba Bhag Singh

University, Khlala, Jalandhar,

Punjab, India
Corresponding Author: Dr. Amrita Kumari Sant Baba Bhag Singh

University, Khlala, Jalandhar,

Punjab, India

\section{Effect of insect pollinators on quantitative and qualitative parameters of apple in Kashmir}

\author{
Amanullah Tantray and Dr. Amrita Kumari
}

DOI: https://doi.org/10.22271/j.ento.2020.v8.i5t.7707

\begin{abstract}
Pollination is most important process for the efficiency of the vast majority of the yields in agrarian and horticultural ecosystems. Apple inflorescence needs assistance from insect pollinators like honey bees to carry out the process of pollination and hence more the number of pollinators, higher the chance for better crop quality and yield. Research was carried out to analyze the effect of pollinators on qualitative and quantitative parameters of apple in Kashmir. Three colonies of Apis mellifera L. were placed in two different orchards with pollinizer ratio of 5\% and 10\%. Data yielded revealed that the controlled release of three hive units in orchard with 10 per cent pollinizer ratio showed significantly better results both quantitatively and qualitatively, for example fruit size $(78.733 \pm 0.255 \mathrm{~mm})$, fruit diameter $(77.732 \pm 0.687$ $\mathrm{mm})$, fruit weight $(237.285 \pm 5.702 \mathrm{~g})$, fruit volume $(250.476 \pm 3.904 \mathrm{ml})$ and fruit colour $(98.95 \%)$ as compared to naturally pollinated orchards with $10 \%$ pollinizer proportion. Similarly, controlled release with three hives in orchard with $5 \%$ pollinizer proportion also gives a standard quality fruit (size; $72.744 \pm 0.792 \mathrm{~mm}$ and diameter; $72.595 \pm 0.184 \mathrm{~mm}$ ) with a good commercially profitable yield (256 $\mathrm{kg} /$ tree) over naturally pollinated orchard (5\% pollinizer proportion). These studies revealed that in orchards with inadequate pollinizer ratio, growers can increase their quality and yield by controlled release of three hives of Apis mellifera which can significantly increase the production and can improve the quality of fruit.
\end{abstract}

Keywords: Apple, insect pollinators, pollination, pollinator

\section{Introduction}

Jammu and Kashmir is known as the 'Apple bowl' of India. The total area under apple cultivation in Jammu and Kashmir is 3.87 lakh hectares. Apple is one of the important cash crops of Kashmir and needs cross pollination. For better quality and quantity it needs appropriate and compatible plant called pollinizer and the pollen carriers known as pollinators. Cross pollination is major mechanism to increase the quality and yield of apple crop. Apis mellifera that is also known as European bee is most widely used insect for the cross pollination of apple.

The Honey bees act as ideal pollinators for pollination in apple orchads. They form colonies and each colony produces many foraging bees. They can move into the apple orchads in flowering periods, their body parts pick up the pollen grains, they can work for longer hours show the flower consistency and adapted to different climates [6]. Another type of insect pollinator that do not paly so important role in cross pollination for apple is Syrphid flies or hover flies. However, relatively little research into fly pollinator has been conducted as compared to honey bees. Bees are an enormously diverse group. There are over 20, 000 species of bees in the world ${ }^{[14]}$ approximately 679 Species of bees in India ${ }^{[1]}$.The number of bee species that frequently visit the apple orachds are 37 bee species belonging to 15 genera and 6 families. Family apidae was the dominant group of bees with 13 species followed by Helictidae (11 species) ${ }^{[9]}$ while focusing on distributional diversity of insect pollinators on single plant species of apple (Malus domestica) reported the diversity of Helicted bees (sweat bees) surpassing other pollinators in the Kashmir valley. The ecological relationship of the pollinators was recognized long before by ${ }^{[9]}$ that cross pollination is the only means of maintaining the ecological diversity. Good pollination improves both yield and size of the fruit [7].

A number of recent studies in agricultural systems have suggested that native bees play an important role in crop pollination ${ }^{[10]}$. 
Both yields of fruit, legumes and vegetable seeds often have been doubled or tripled by providing adequate number of bees for pollination McGregor, 1976). Globally, the annual contribution of pollinators to the agricultural crop has been estimated at about US\$54 billion [3]. Among the dipteran pollinators the Syrphidae is a large $(6,000 \pm$ world spp.) family with striking flies of much diversity, and about 500 species have been found in Indian subcontinent so far and under the right conditions numerous species can be very abundant and very little work has been done on fly (Diptera) ${ }^{[17]}$. In Jammu \& Kashmir syrphidae family is represented by 90 species belonging to 40 genera (Ghorpede personal communication).

\section{Materials and Methods}

An extensive study was carried out for two consecutive years in Kashmir during 2018-19, four orchards were selected, two orchards (T1 \& T3) with controlled release of three hives (Apis mellifera) having 5 and 10 percent pollinizer ratio and another two orchards (T2 \& T4) of each category were kept as control I.e. natural pollination). Before the initial bloom, the bee colonies with 9-10 frame strength were evenly spaced in the orchards for two days. For assessing the cumulative impact of pollinators and pollinizer ratio on quality and yield of apple fruit, 10 apple trees of Red delicious variety of ten uniform size, age and vigor were taken from the orchads of district kulgam of Jammu and Kashmir. The data regarding assessed parameters were studied as per methodology ascribed [5] and using "Apple Descriptor" (UPOV) by International Union for The Protection of New Varieties of Plants, Geneva, (2005-2006).

During the study in full booming period, four branches with at least 50 flowers / branch were selected from the four equidistant quadrants of the tree and tagged to study the following parameters .Flower intensity was determined as per apple descriptor (UPOV) taking 3 as light, 5 as moderate and 7 as heavy. Fruit set (spur basis) was recorded 10 days after petal fall and percentage was measured as follows:Fruit drop was determined based on initial fruit-set as the number of fruits dropped. Fruit- retention was recorded one week before harvesting of fruit as fruits retained finally at maturity. Fruit yield was calculated as the number of fruits ( $\mathrm{Kg} /$ tree) harvested from each tree. The improvement in the quality of fruit was assessed on a sample of 20 apples taken from each replicate tree from each orchard after harvesting in terms of weight, size, diameter, shape, colour, volume and number of seeds per fruit. Fruit size $(\mathrm{mm})$ and Diameter $(\mathrm{mm})$ was determined with the help of Vernier caliper taking $<65 \mathrm{~mm}$ as small, $65-70 \mathrm{~mm}$ as medium and $>70 \mathrm{~mm}$ as large. Fruit shape was observed as per ${ }^{[18]}$ taking 3 as conical, 5 as round and 7 as oval. Fruit colour was depicted as per apple descriptor (UPOV) depicting 2 as orange, 4 as red, 6 as purple and 8 as brown. Fruit weight was measured by top pan analytical balance. Fruit volume (ml) was determined by Water displacement method on the line of the principle that the volume of an object is equal to the amount of water displayed by it. Number of seeds/ fruit was counted by longitudinally cutting the fruit into two equal halves. Data were analyzed statistically.

\section{Results and Discussions}

The data documented in Table-1 revealed that all the four different treatments viz., controlled release of 3 hives in orchard with $5 \%$ pollinizer ration (T1), naturally pollinated orchards with $5 \%$ pollinizer ratio (T2), controlled release pollination of 3 hives in orchard with $10 \%$ pollinizer ratio (T3), and naturally pollinated orchards with $10 \%$ pollinizer ratio (T4) differ significantly with respect to different quantitative characteristics observed. Average flower intensity does not reveal any significant difference, while rest of the parameters differed significantly. Controlled release pollination of 3 hives in orchard with $10 \%$ pollinizer ratio (T3), being superior with high initial fruit set/50 flowers $(42.288 \pm 0.902)$, per cent fruit set $(70.07 \%)$, fruit retention at maturity $(35.188 \pm 0.515)$ and yield $(303.70 \mathrm{~kg} /$ tree $)$ but with minimum drop $(10.49 \%)$ compared to natural pollinated orchards with $10 \%$ pollinizer ratio (T4) in which case the initial fruit set/50 flowers $(20.925 \pm 0.497)$, per cent fruit set $(21.69 \%)$, fruit retention $(10.950 \pm 0.574$ and yield $(128.90 \mathrm{~kg} /$ tree) with maximum fruit drop $(44.44 \%)$ was observed. Similarly, treatment T1 having better initial fruit set/50 flowers $(35.350 \pm 0.740)$, percent fruit set $(61.925 \%)$, fruit retention $(31.075 \pm 0.483)$, yield $(256.55 \mathrm{~kg} /$ tree $)$ and fruit drop (12.87\%), in comparison to treatment (T2) in which case initial fruit set/50 flowers, percent fruit set, fruit drop, fruit retention and yield of $19.1 \pm 0.531,19.200$ per cent, 47.99 per cent, $9.475 \pm 0.538$ and $113.05 \mathrm{~kg} /$ tree respectively, was observed.

Table 1: Average effect of insect pollinators vis - a - vis pollinizer ratio on the quantitative parameters of apple during 2018 - 2019

\begin{tabular}{|c|c|c|c|c|c|c|}
\hline \begin{tabular}{c|} 
Treatments \\
Retention Intensity
\end{tabular} & $\begin{array}{c}\text { Flower } \\
\text { set }\end{array}$ & Initial Fruit & $\begin{array}{c}\text { Fruit Drop after June } \\
\text { Drop }\end{array}$ & $\begin{array}{c}\text { Percent Fruit Set } \\
\text { at Maturity }\end{array}$ & Fruit $(\mathrm{kg} /$ tree $)$ & Fruit Yield \\
\hline $\mathrm{T} 1$ & $7(32.58 \pm 1.06)$ & $35.350 \pm 0.740$ & $4.550 \pm 0.296(12.87 \%)$ & $61.925 \pm 1.057$ & $31.075 \pm 0.483$ & $256.55 \pm 0.497$ \\
\hline $\mathrm{T} 2$ & $7(31.5 \pm 3.17)$ & $19.100 \pm 0.531$ & $9.175 \pm 0.503(47.99 \%)$ & $19.200 \pm 1.076$ & $9.475 \pm 0.538$ & $113.05 \pm 0.975$ \\
\hline $\mathrm{T} 3$ & $7(340.5 \pm 2.71)$ & $42.288 \pm 0.902$ & $4.438 \pm 0.236(10.49 \%)$ & $70.075 \pm 0.515$ & $35.188 \pm 0.515$ & $303.70 \pm 2.525$ \\
\hline $\mathrm{T} 4$ & $7(32.65 \pm 3.17)$ & $20.925 \pm 0.497$ & $9.300 \pm 0.497(44.44 \%)$ & $21.690 \pm 2.001$ & $10.950 \pm 0.574$ & $128.950 \pm 1.465$ \\
\hline Mean & $7(32.69)$ & 29.42 & 6.87 & 43.22 & 21.67 & 210.56 \\
\hline C.D $(\mathrm{pd} * 0.05)$ & NS & 0.90 & 0.4 & 1.62 & 0.620 & 1.833 \\
\hline \multicolumn{3}{|c|}{ Legend: Flower Intensity } & UPOV No. & & & \\
\hline \multicolumn{7}{|c|}{ Flowers $/ 30 \mathrm{~cm}$ branch } \\
\hline \multicolumn{3}{|c|}{ Light $(15-2)$} & 3 & & & \\
\hline \multicolumn{3}{|c|}{ Moderate $(21-30)$} & 5 & & & \\
\hline \multicolumn{3}{|c|}{ Heavy $(31-35)$} & 7 & & & \\
\hline
\end{tabular}

Values are mean $\pm \mathrm{Cl}$ (confidence interval) of $\mathrm{N}=20, \mathrm{~T} 1-5 \%$ pollinizer ratio +3 hives, $\mathrm{T} 2-5 \%$ pollinizer ratio $+\mathrm{Natural}$ pollination, $\mathrm{T} 3-$ $10 \%$ pollinizer ratio +3 hives, $\mathrm{T} 4-10 \%$ pollinizer ratio + Natural pollination 
The data recorded on various qualitative characteristics enumerated in Table -2 . Results obtained indicate that the improvement in fruit quality with respect to fruit diameter $(78.733 \pm 0.255 \mathrm{~mm})$, fruit size $(72.595 \pm 0.184 \mathrm{~mm})$, fruit weight $(237.285 \pm 5.702 \mathrm{~g})$, fruit volume $(250.476 \pm 3.904 \mathrm{ml})$, fruit colour $(98.95 \%)$, fruit shape (conical) and seed number (9.373/fruit) was pronounced more in treatment T3 followed by treatment $\mathrm{T} 1$ in which the fruit diameter $(72.744 \pm 0.782 \mathrm{~mm})$, fruit size $(72.595 \pm 0.184 \mathrm{~mm})$, fruit weight $(172.555 \pm 1.879 \mathrm{~g})$, fruit volume $(188.128 \pm 0.748 \mathrm{ml})$, fruit colour $(94.65 \%)$, fruit shape (conical) and seed number (8.173/fruit) was observed compared to $\mathrm{T} 4$ with fruit diameter $(66.614 \pm 0.477 \mathrm{~mm})$, fruit size $(60.203 \pm 0.256 \mathrm{~mm})$, fruit weight $(124.940 \pm 3.198 \mathrm{~g})$, fruit volume $(114.748 \pm 0.498 \mathrm{ml})$, fruit colour $(67.45 \%)$, fruit shape (round with conical base) and seed number (4.063) and treatment $\mathrm{T} 2$ with fruit diameter $(61.957 \pm 0.207 \mathrm{~mm})$, fruit size $(53.366 \pm 0.399 \mathrm{~mm})$, fruit weight $(113.863 \pm 1.208 \mathrm{~g})$, fruit volume $(131.602 \pm 1.883 \mathrm{ml})$, fruit colour $(54.75 \%)$, fruit shape (conical) and seed number (3.648/fruit).

Table 2: Average effect of insect pollinators vis - a - vis pollinizer ratio on the quality of apple during $2018-2019$

\begin{tabular}{|c|c|c|c|c|c|c|c|}
\hline $\begin{array}{c}\text { Treatments } \\
\text { Over colour intensity }\end{array}$ & $\begin{array}{c}\text { Diameter } \\
(\mathbf{m m})\end{array}$ & $\begin{array}{c}\text { Size } \\
(\mathbf{m m})\end{array}$ & $\begin{array}{c}\begin{array}{c}\text { Volume } \\
(\mathrm{ml})\end{array} \\
\end{array}$ & $\begin{array}{l}\text { Weight } \\
\text { (g) }\end{array}$ & $\begin{array}{l}\text { Seed } \\
\text { (No.) }\end{array}$ & $\begin{array}{c}\text { Fruit } \\
\text { Colour }\end{array}$ & Fruit Shape \\
\hline $\mathrm{T} 1$ & $72.744 \pm 0.782$ & $72.595 \pm 0.184$ & $172.555 \pm 1.879$ & $188.128 \pm 0.748$ & $8.173 \pm 0.1304$ & $4(94.65 \%)$ & $3.4(3-5)$ \\
\hline $\mathrm{T} 2$ & $61.957 \pm 0.207$ & $53.366 \pm 0.399$ & $113.863 \pm 1.208$ & $131.602 \pm 1.883$ & $3.648 \pm 0.0524$ & $3(54.75 \%)$ & $5.5(5-7)$ \\
\hline T3 & $78.733 \pm 0.255$ & $77.732 \pm 0.687$ & $237.285 \pm 5.702$ & $250.476 \pm 3.904$ & $9.373 \pm 0.0844$ & $4(98.95 \%)$ & $3.2(3-5)$ \\
\hline $\mathrm{T} 4$ & $66.614 \pm 0.0477$ & $60.203 \pm 0.256$ & $124.940 \pm 3.198$ & $114.748 \pm 0.498$ & $4.063 \pm 0.1344$ & $3(67.45 \%)$ & $5.3(5-7)$ \\
\hline Mean & 70.012 & 65.974 & 162.161 & 171.239 & 6.314 & \multicolumn{2}{|c|}{$\begin{array}{l}\text { Visualized as per Apple } \\
\text { Descriptor }\end{array}$} \\
\hline C.D (pd*0.05) & 0.642 & 0.605 & 3.560 & 2.750 & 0.132 & & \\
\hline Legend: & Fruit Shape & UPOV No. & Fruit Colour & UPOV No. & \multicolumn{3}{|c|}{ Intensity Scale (over colour) } \\
\hline \multirow[t]{4}{*}{ Conical } & 3Orange & 2 & $1(0-25 \%)$ & & & & \\
\hline & Round & 5 & Red & 4 & \multicolumn{3}{|c|}{$2(26-50 \%)$} \\
\hline & Oval & 7 & Purple & 6 & \multicolumn{3}{|c|}{$3(51-75 \%)$} \\
\hline & & & Brown & 8 & \multicolumn{3}{|c|}{$4(75-100 \%)$} \\
\hline
\end{tabular}

Values are Mean \pm 1 (confidence interval) of $\mathrm{N}=20 . \mathrm{T}_{1}-5 \%$ pollinizer ratio +3 hives, $\mathrm{T}_{2}-5 \%$ pollinizer ratio + Natural pollination, $\mathrm{T}_{3}-10 \%$ pollinizer ratio +3 hives, $\mathrm{T}_{4}-10 \%$ pollinizer ratio + Natural pollination

The extensive studies on impact of pollinators on apple crop revealed that quantitative and qualitative parameters were found to be influenced significantly because of interaction between the pollinator population present and the pollinizer proportion in the orchard. However, pollination efficiency in terms of enhancement of fruit set, fruit retention, yield and reduction in fruit drop increased by placing three Apis mellifera L. colonies in orchards with $10 \%$ pollinizer ratio. Significantly superior results in terms of quality were obtained in orchards where honey bees were introduced over control, this may be due to adequate pollinizer ratio accompanied by increased pollination ${ }^{[12]}$. The results are in conformity with the findings of ${ }^{[2]}$, which reported that increase in fruit set (37.75\%) and fruit yield (38.39 tonnes/ha) with placement of three colonies was significantly higher in the orchards with sufficient pollinizers $(>10 \%)$ as compared to the pollinizer deficient orchards $(<10 \%)$ having fruit-set and fruit yield of 21.75 percent and 17.47 tonnes/ha, respectively. Similar findings were reported by ${ }^{[8]}$ which recorded a fruit-set of 78.80 per cent, when three honeybee colonies were placed in the orchards with $10 \%$ pollinizer proportion ${ }^{[15]}$ determined a significant increase in per cent fruit set $(32.48$ to $53.55 \%)$, fruit retention (23.38-46.14) and reduction in fruit drop (29.23-12.13\%) with increase in Apis mellifera colonies from $0-4$ in apple orchards having adequate pollinizer proportion compared to orchards with low pollinizer proportion. Besides, study also revealed that pollinators vis- a vis., pollinizer ratio can influence fruit quality by increasing the seed number which affect the sink strength of individual fruits, probably through hormones. The results are in line with the findings ${ }^{[2,11]}$ demonstrated that the fruit quality (fruit size-10.5-13cm and seed number $10-15$ per fruit) were higher when the main commercial cultivars were benefited with pollinizers (10\%) and pollinators (2-
3 colonies/ha). Besides, there are evidences that levels of pollination affects quality of fruits [19, 4, 13]. Similarly, [8] reported that sufficient pollinators (4-5 colonies/ ha) together with suitable pollinizer proportion (10\%) enhances the cross pollination resulting in consistent quality fruit with sufficient number of seeds (9-10/fruit).

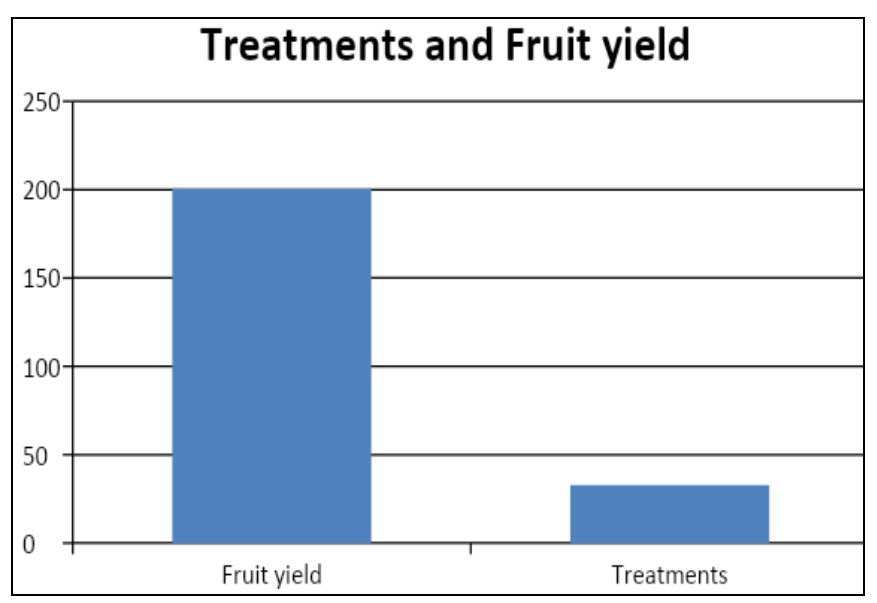

Fig 1: Graphical representation showing an increase in fruit yield $/ \mathrm{kg} /$ tree with treatments.

\section{Conclusion}

Insect Pollinators are very important agencies for the pollination in Apple orchads. This study is useful for students, scientists and also useful to check the effects of different pollinators on qualitative and quantitative traits of apple in Kashmir. If some control measure technique could came out during the study. It is also to be monitored. 


\section{Acknowledgement}

The authors would like to thank, prof. Syed Tanveer, Head of department, university of Kashmir for guidance and providing support for carrying out this work

\section{References}

1. Ascher JS, Pickering. Discover Life bee species guide and world checklist (Hymenoptera: Apoidea: Anthophila). Bugguide. Net. 2018; 47:1-20.

2. Anand R, Sharma G, Roshan A, Sharma OC. Floral biology and effect of pollination in apple (Malus domestica). Indian J. Agricultural Sciences. 2003; 75(10):667-669.

3. Buchmann, Stephen L. The Forgotten Pollinators. Island Press/shearwater, Washington D.C. 1996.

4. Buccheri M, Di Vaio C. Relationship among seed number, quality and calcium content in apple fruits. $\mathbf{J}$ Plant Nutrition. 2004; 27:1735-1746.

5. Dulta PC. Role of insect pollinators on yield and quality of apple fruit. Indian J. Horticulture. 1986; 44:274-279.

6. Free JB. Insect Pollination of Crops. 2nd edition, Academic press, London, 1993.

7. Gautier-Hion A, Maisels F. Mutualism between a leguminous tree and large African monkeys as pollinators. Behavioural Ecology. 1994; 34:203-210.

8. Gautam, DR, Jindal KK, Sharma G. Fruit Setting Problems of Apples under Changing Climatic Scenario of North Western Himalayas of India. Proc. VIIth IS on TZFTS. Acta Hort. 2004; 662:435-441.

9. Knutson RD, Taylor RG, Penson BJ, Smith GE. Economic Impacts of Reduced Chemical Use. Knutson and Associates, College Station, Texas, 1990, 30- 31.

10. Kremen C, Williams NM, Thorp RW. Crop pollination from native bees at risk from agricultural intensification. Proceedings of Natural Academy and Science USA. 2002; 99:16812-16816.

11. Khan MR. The role of honey bees Apis mellifera $L$. (Hymenoptera: Apidae) in pollination of apple. Pakistan J. Biological Sciences. 2004; 7(3):359-362.

12. Mattu VK, Raj H. Quantitative and Qualitative effects of Honey bee pollination on Apple crop in Shimla Hills of Westeran Himalaya, India, International $\mathbf{J}$ Advanced Biological Research. 2013; 3(3):354-359.

13. Matsumoto, Soejima J, Maejima T. Influence of repeated pollination on seed number and fruit shape of 'Fuji' apples. Scientia Horticulturae. 2012; 137:131-137.

14. Michener CD. Bees of the World. Johns Hopkins Press, Baltimore, MD. Mcgregor, S. E. 1976. Insect pollinators of cultivated crop plants. United State Department of Agriculture, Agriculture Hand Book, 2007.

15. Rana B.S, Goutam D.R, Goyal N.P, Sharma H.K. Effect of honey bee pollination on yield parameters of apple in relation to pollinizer proportion. Indian Bee. J. 1998; 60(1):9-11.

16. Rana RS, Bhagata RS, Kalia V, Lal H. 'Impact of climate change on shift of apple belt in Himachal Pradesh. ISPRS Archives XXXVIII-8/W3 Workshop Proceedings: Impact of Climate Change on Agriculture, 2009.

17. Ssymank A, Kearns CA, Pape T, Thompson FC. Pollinating Flies (Diptera): A major contribution to plant diversity and agricultural production. Tropical Conservation. 2008; 9(1\& 2):86-89.

18. UPOV “Apple Descriptor". Guidelines for the conduct of tests for Distinctness, uniformity and Stability by
International Union for The Protection of New Varieties of Plants, Geneva, 2005.

19. Volz R.K, Tustin D.S, Ferguson I. B. Pollination effects on fruit mineral composition, seed and cropping characteristics of 'Braeburn' apple tree. Scientia Horticulturae. 1996; 66:169-180. 